\title{
CARACTERIZACIÓN MOLECULAR Y PATOGÉNESIS DE Fusarium ASOCIADO AL AMARILLAMIENTO DEL TRIGO
}

\section{MOLECULAR CHARACTERIZATION AND PATHOGENESIS OF Fusarium ASSOCIATED TO WHEAT YELLOWING}

\section{A. Eugenia Rangel-Castillo', Ernestina Valadez-Moctezuma² y Héctor Lozoya Saldaña}

\author{
'Posgrado en Protección Vegetal, Departamento de Parasitología Agrícola. ${ }^{2}$ Instituto de Horticultura, Departamento de Fitotecnia, Universidad Autó- \\ noma Chapingo, 56230, Chapingo, México.

\section{RESUMEN}

El amarillamiento o madurez prematura del trigo (Triticum aestivum L.) es una enfermedad causada por un complejo de especies del género Fusarium que ataca cualquier parte de la planta. Este problema se ha reportado en diversos municipios del estado de Guanajuato, México desde el año 2000. El objetivo del presente trabajo fue aislar, caracterizar e identificar especies de Fusarium asociadas al amarillamiento del cultivo de trigo en ocho localidades de Guanajuato y cuantificar su patogenicidad. Se obtuvieron 116 aislamientos de diferentes órganos de plantas con síntomas que fueron caracterizados molecularmente con ITS-RFLP, ISSR e identificados con las secuencias del gen EF1-a. Los fragmentos RFLP de la región ITS y la técnica ISSR conformaron distintos agrupamientos. Las secuencias del gen EF1-a identificaron cercanamente a los aislamientos con las especies $F$. proliferatum, F. subglutinans, $F$. oxysporum, $F$. thapsinum y $F$. andiyazi. Se observó gran amplitud de severidad en las pruebas de patogenicidad (de 2.2 a $39.7 \%$ ). La mayor agresividad se identificó en la cepa T5.10 (F. proliferatum), así como en efecto conjunto de las cepas R8.5 (F. proliferatum) y E5.3 (no identificada).

Palabras clave: Triticum aestivum, ITS, ISSR, RFLP, patogenicidad, agrupamiento genético.

\section{SUMMARY}

Yellowing or early maturity of wheat (Triticum aestivum L.) is a disease caused by a complex of Fusarium species that may attack any part of the plant. This problem has been reported in several municipalities of the state of Guanajuato, México since the year 2000. This study isolated, characterized and identified the Fusarium species associated with the yellowing or early maturity of wheat in eight localities of Guanajuato; it also quantified their pathogenicity. One hundred and sixteen isolates from different organs of plants with symptoms were molecularly characterized by using ITS-RFLP, ISSR and identified with EF1- $a$ gene sequences. The RFLP fragments from the ITS region and the ISSR technique produced different clusters. EF1-a gene sequences closely identified the isolates with the species F. proliferatum, F. subglutinans, F. oxysporum, $F$. thapsinum, and $F$. andiyazi. A wide severity range was observed in the pathogenicity tests (from 2.2 to $39.7 \%$ ). The highest aggressiveness was identified in strain T5.10 (F. proliferatum), as well as in a combined effect of strains R8.5 (F. proliferatum) and E5.3 (unidentified).

Index words: Triticum aestivum, ITS, ISSR, RFLP, pathogenicity, genetic grouping.

\section{INTRODUCCIÓN}

El cultivo de trigo (Triticum aestivum L.) es uno de los más importantes para el consumo humano, ocupa el cuarto lugar en producción a nivel mundial, tan solo por detrás de la caña de azúcar (Saccharum officinarum L.), maíz (Zea mays L.) y arroz (Oryza sativa L.) (FAOSTAT, 2015). En México, en el año 2015, el estado de Guanajuato ocupó el tercer lugar nacional tanto en superficie sembrada como en valor de la producción (SIAP, 2015).

El cultivo está expuesto a una gran amplitud de plagas y enfermedades que merman la calidad y la producción, entre ellas, el amarillamiento o madurez prematura, que es una enfermedad causada por una o más especies del género Fusarium, como F. verticillioides (sin. F. moniliforme) (Gibberella fujikuroi) y F. graminearum (G. zeae), entre otros. Ataca cereales como trigo, cebada (Hordeum vulgare L.), centeno (Secale cereale L.), avena (Avena sativa L.), maíz, sorgo [Sorghum bicolor L. (Moench)], triticale (Triticosecale) y diferentes forrajes. Otros hospederos son frijol (Phaseolus vulgaris L.), soya (Glycine max L. Merr.) y girasol (Helianthus annuus L.).

Las especies F. culmorum y F. graminearum están particularmente asociadas a trigos con agobio hídrico. Fusarium avenaceum, F. acuminatum, F. crookwellense y F. poae son menos virulentas y mayormente asociadas con las pudriciones de raíz y corona. La especie F. graminearum del Grupo II también se asocia a estas pudriciones. Las especies antes mencionadas sobreviven en el suelo y en rastrojos en forma de clamidosporas (Gilchrist-Saavedra et al., 2005; Wall, 1988).

Desde el año 2000, en Guanajuato se ha reportado la enfermedad en los municipios de Pueblo Nuevo, Salamanca, Valle de Santiago, Pénjamo, Yuriria, Irapuato y Acámbaro (SARH, 1992). En el campo se presenta en forma de 
manchones con síntomas de daño en raíz, espiga y tallo. Cuando se le ubica en grandes extensiones puede llegar a causar pérdidas totales en la producción de grano. Es importante identificar las especies de este hongo para entender la relación que tienen entre sí en el desarrollo de la enfermedad.

Las estrategias clásicas para el estudio de la variabilidad genética tales como anatomía comparativa, morfología, embriología y fisiología se han visto complementadas en gran medida por técnicas moleculares basadas en los polimorfismos de ADN o de proteínas (Doyle y Doyle, 1987; González y Simpson, 1997; Vega-Ramos et al., 2013), recientemente aplicadas en Fusarium de cereales (Albayrak et al., 2016; Consolo et al., 2015). Por tal motivo el objetivo del presente estudio fue caracterizar e identificar molecularmente y evaluar la patogenicidad de las especies de Fusarium asociadas al amarillamiento o madurez prematura en el cultivo de trigo en el sur del Bajío guanajuatense.

\section{MATERIALES Y MÉTODOS}

\section{Muestreos, aislamientos e identificación morfológica de Fusarium spp.}

Se realizaron ocho muestreos dirigidos durante el ciclo agrícola otoño-invierno 2012-2013 en áreas productoras del suroeste del estado de Guanajuato (Figura 1). En los materiales colectados se hicieron cortes de tejido de raíz $(R)$, espiga (E) y tallo ( $T$ ) de cada una de las muestras (Cuadro 1), seguidos de lavados con hipoclorito de sodio comercial $25 \%$ (vol-vol) y alcohol etílico $70 \%$. Se sembraron en medio de papa dextrosa agar (PDA) y se incubaron a $27^{\circ} \mathrm{C}$. Se utilizó la técnica de cultivos monospóricos para obtener cultivos puros (French y Hebert, 1982). Para el reconocimiento morfológico de los aislados se utilizaron las claves taxonómicas de Barnett y Hunter (1972) y de Nelson et al. (1983), para lo cual se colocaron fragmentos de agar con cada cepa de aproximadamente $0.5 \mathrm{~cm}^{2}$ en el centro de una caja Petri con los medios PDA, agar-agua o medio Czapek para evaluar su desarrollo. Para la esporulación se utilizó el medio de cultivo agar-agua con hoja de clavel que consistió en transferir el fragmento de $0.5 \mathrm{~cm}^{2}$ de cada cepa en el centro de una caja Petri y alrededor del fragmento, a $1.5 \mathrm{~cm}$ de distancia, se colocaron fragmentos de $2 \mathrm{~cm}$ de hojas de clavel previamente esterilizadas. Se incubaron a $27^{\circ} \mathrm{C}$ hasta que el hongo creció sobre las hojas de clavel, donde se observaron estructuras reproductoras.

\section{ADN: Análisis moleculares y agrupamientos}

\section{Extracción}

Se utilizó el método CTAB (bromuro de hexadeciltri- methylamonio) $2 \%$. Con espátula estéril se extrajo micelio de cada uno de los aislamientos recuperados y crecidos a partir de la orilla del crecimiento activo, y se procedió a la extracción y purificación del ADN de acuerdo con Doyle y Doyle (1987) y Weising et al. (2005). Al final del proceso, la pastilla de ADN se resuspendió en $100 \mu \mathrm{L}$ de TE (Tris-EDTA pH 8.0) y se almacenó a $-20^{\circ} \mathrm{C}$.

La calidad del ADN se determinó mediante electroforesis en gel de agarosa $1 \%$. Para el revelado del gel se utilizó una solución de bromuro de etidio $\left(0.5 \mu \mathrm{g} \mathrm{mL}^{-1}\right)$ y se fotodocumentó en un sistema modelo Universal Hood II, BIORAD ${ }^{\circledR}$ con el programa QuantityOne®.

\section{ITS-RFLP}

Con la finalidad de reducir el número de aislamientos purificados y sólo considerar aquellos que resultaran diferentes con fines de identificación molecular, se analizó con enzimas de restricción la zona de los espaciadores internos transcritos (ITS) del ADN ribosomal que es variable y específica en cada género/especie. Se utilizaron los iniciadores ITS5 (5'-GGA-AGT-AAA-AGT-CGT-AAC-AAG-G-3') y NL4 (5'-GGA-TTC-TCA-CCC-TCT-ATG-AC-3') descritos por White et al. (1990) y O'Donnell (1992) que amplifican un fragmento de aproximadamente 1200 pb en el género Fusarium. Las condiciones de termociclaje fueron: desnaturalización inicial de $95^{\circ} \mathrm{C}$ por 4 min, 35 ciclos $\left(94^{\circ} \mathrm{C}\right.$ por $1 \mathrm{~min} ; 58^{\circ} \mathrm{C}$ por $1 \mathrm{~min} ; 72^{\circ} \mathrm{C}$ por $2 \mathrm{~min}$ ) y un ciclo de extensión final de $72^{\circ} \mathrm{C}$ por $10 \mathrm{~min}$. Los productos de la PCR se visualizaron en geles de agarosa $1.2 \%$.

Los polimorfismos de longitud de fragmentos de restricción (RFLP) son secuencias específicas de nucleótidos en el ADN, reconocidas por endonucleasas, que al variar entre individuos les confieren especificidad para su diferenciación (Azofeifa-Delgado, 2006; Valadez y Kahl, 2005). Para esta técnica se utilizó el producto de ITS obtenido en cada uno de los aislados y se cortó con las enzimas de restricción Hinf I, Hha I y Hae III. La reacción de digestión se preparó de acuerdo con las especificaciones de cada fabricante. Para la visualización de los cortes producidos por las enzimas se utilizaron geles de acrilamida $6 \%$.

\section{PCR-ISSR}

Con la finalidad de conocer la variabilidad genómica entre los diferentes aislados de Fusarium se utilizó la técnica Inter Simple Sequence Repeats basada en PCR. Esta técnica amplifica fragmentos ubicados entre dos microsatélites del mismo tipo (que presentan la misma unidad repetitiva) pero de forma invertida con respecto a orientación de las dos hebras de ADN (Azofeifa-Delgado, 2006; Sánchez-Coello et al., 2012). Se utilizaron los iniciadores 


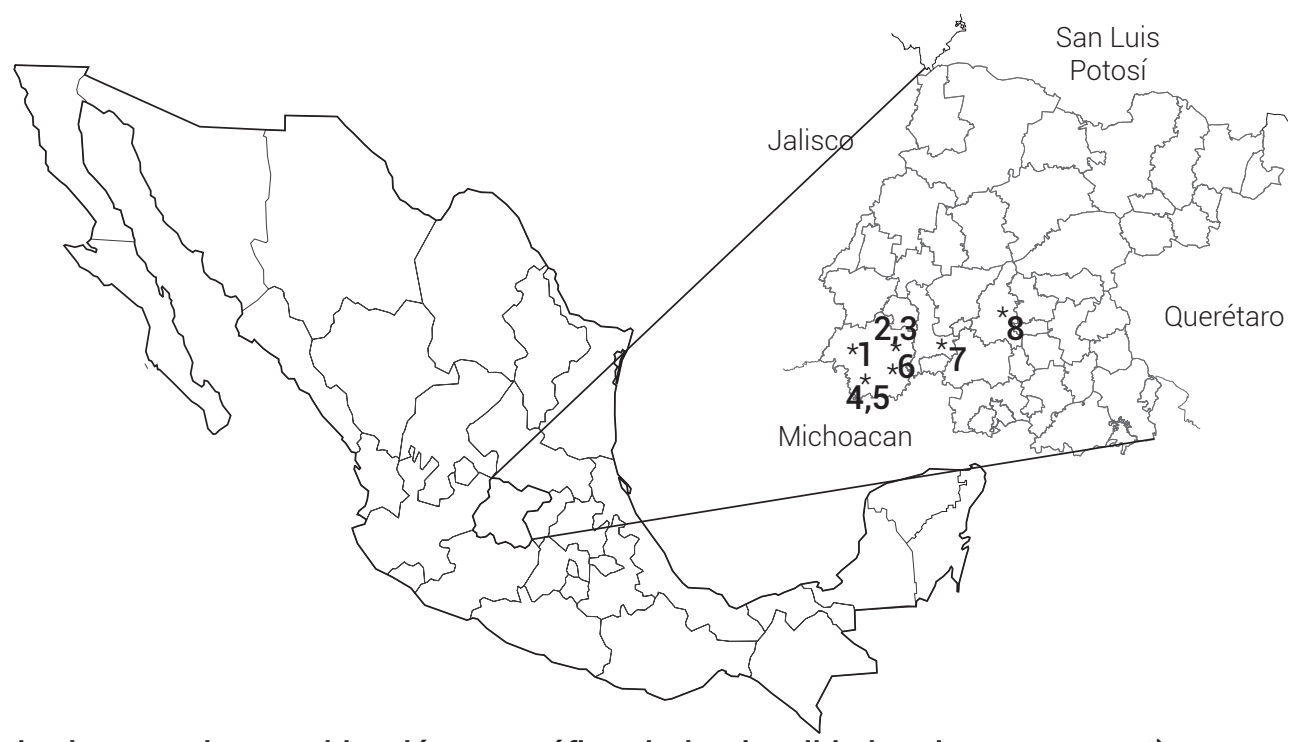

Figura 1. Estado de Guanajuato. Ubicación geográfica de las localidades de muestreo. 1) Las Jaras, Pénjamo, Gto., 20.37663, -101.919090, 1674; 2) La Estrella-1, Pénjamo, Gto., 20.37656, -101.92329, 1675; 3) La Estrella-2, Pénjamo, Gto., 20.37656, -101.92329, 1675, 4) Colorado de Herrera, Pénjamo, Gto., 20.31386, -101.83695, 1685; 5) La Estación, Pénjamo, Gto., 20.38724, -101.70074, 1704; 6) Vista hermosa, Pénjamo, Gto., 20.38581, -101.69075, 1701; 7) Maritas, Abasolo, Gto., 20.32413, -101.59092, 1716 y 8) Los Prietos, Salamanca, Gto., 20.60720, - 101.26907, 1713. Para todas las localidades el orden la numeracion corresponde a: latitud, longitud y altitud (msnm).

(AC)8YG y $\mathrm{AC}(\mathrm{GACA})_{4}\left(\mathrm{IDT} \mathrm{TM}^{\mathrm{M}}\right.$, EUA). Las condiciones de termociclaje fueron: desnaturalización inicial de $95{ }^{\circ} \mathrm{C}$ por 3 min, 35 ciclos $\left(95^{\circ} \mathrm{C}\right.$ por $30 \mathrm{~s}, 55^{\circ} \mathrm{C}$ por $45 \mathrm{~s}, 72{ }^{\circ} \mathrm{C}$ por 2 min) y un ciclo de extensión final de $72{ }^{\circ} \mathrm{C}$ por $10 \mathrm{~min}$. Para la separación de los amplicones se utilizó una cámara vertical de electroforesis en acrilamida $6 \%$ con geles de $31 \times 14 \mathrm{~cm}$. Los geles se revelaron con nitrato de plata de acuerdo con las indicaciones de Sambrook et al. (1989). Una vez documentados los geles se procedió a su análisis, lo que generó una matriz binaria que se llevó al programa FreeTree@ versión 0.9.1.50, mediante el índice Jaccard y el método de construcción de árbol de agrupamiento par con media aritmética no ponderada UPGMA. Para visualizar el dendrograma se utilizó el programa TreeView (C) versión 1.6.6.

\section{Patogenicidad}

Con base en los agrupamientos obtenidos con los datos RFLPs e ISSR (Figuras 4 y 6) y características morfológicas se seleccionó una cepa representante de cada agrupamiento para evaluar la patogenicidad en plántulas de trigo susceptibles a Fusarium de la variedad Cortazar S94. Se aplicaron 28 tratamientos, del 1 al 15 correspondieron a cepas evaluadas de forma individual, mientras que en los tratamientos del 16 al 27 se utilizaron mezclas de cepas inoculadas conjuntamente en las plántulas de trigo (Cuadro 2); el tratamiento 28 representó el testigo negativo solamente tratado con agua. Para la preparación del inoculo, cada hongo se desarrolló en medio PDA a $27^{\circ} \mathrm{C}$ durante
10 d; posteriormente se realizó una suspensión de conidios de cada cepa a una concentración de $1 \times 10^{6}$ microconidios $\mathrm{mL}^{-1}$ de acuerdo con la técnica de French y Hebert (1982).

Las semillas de trigo de la variedad Cortazar S94 se lavaron con una solución de hipoclorito de sodio 2 \% (volvol) durante 1 min y después con agua estéril; enseguida se sumergieron en cada tratamiento durante 10 min y se sembraron cuatro semillas por vaso de unicel con sustrato de vermiculita estéril. El experimento se realizó bajo un diseño completamente al azar de 28 tratamientos con cuatro repeticiones y cada unidad experimental consistió de un vaso con las cuatro plántulas de trigo de la variedad indicada. A los 30 d se lavaron las raíces en cada tratamiento y la severidad de la enfermedad se estimó a través de una escala de daño generada por los autores para el presente trabajo (Figura 2). Los datos obtenidos fueron analizados con el programa SAS (Statistical Analysis System, versión 8) con análisis de varianza y comparación de medias (Tukey, 0.05).

\section{Identificación de especies por secuenciación del gen EF1-a}

Las cepas utilizadas para las pruebas de patogenicidad fueron seleccionadas para identificación molecular por secuenciación del gen EF1-a con los iniciadores EF-1 5'-ATGGGT-AAG-GA(A/G)-GAC-AAG-AC-3' y EF-2 5'-GGA-(G/A) GT-ACC-AGT-(G/C)AT-CAT-GTT-3' (O'Donnell et al., 1998). Las condiciones de termociclaje fueron de un ciclo de 30 


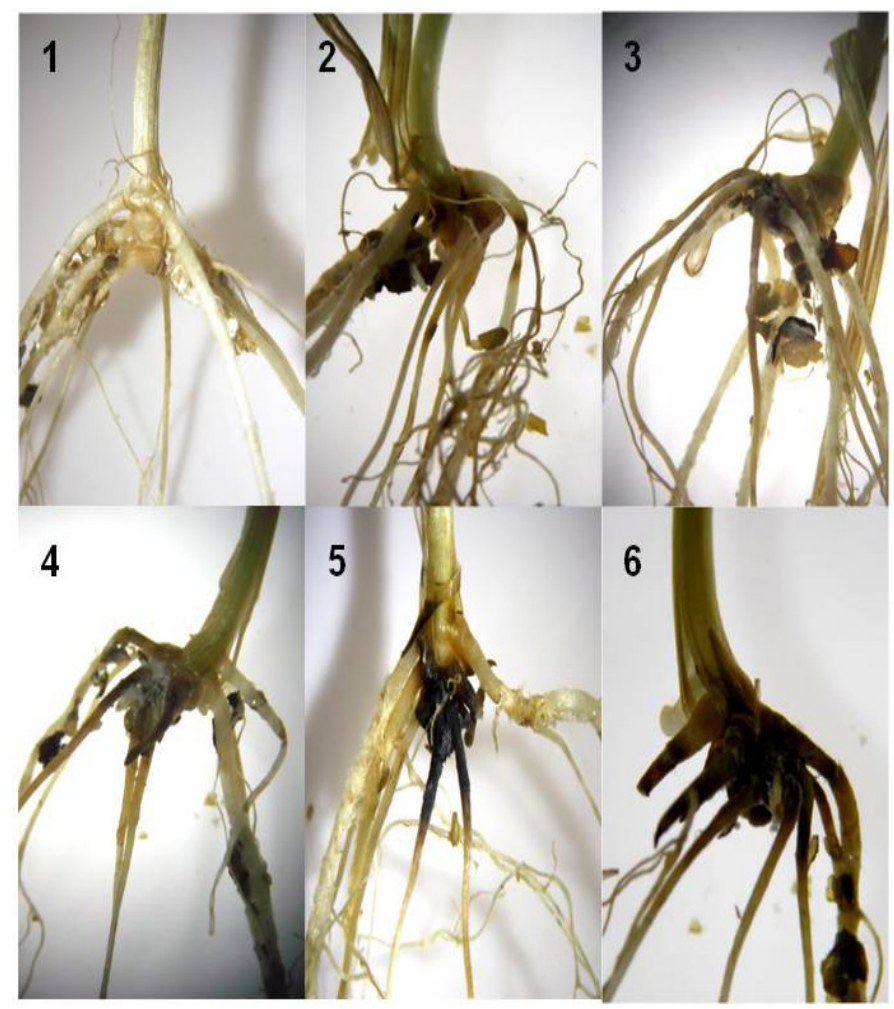

Figura 2. Escala del daño por Fusarium spp. aislado de plantas de trigo con amarillamiento. 1) Planta sana, síntomas no visibles en raíz y corona sin necrosis ni degradación de raíces $(0 \%) ; 2)$ Daño inicial en la raíz, cambio de coloración en una porción de ésta, corona sana (10\%); 3) Avance del daño en raíces que muestra color café (inicio de necrosis) y corona sana (25\%); 4) Degradación de raíces, necrosis e inicio daño en cuello (50\%); 5) Necrosis avanzada del sistema radical y cuello (75\%) y 6) Corona y raíz completamente necrosadas (100\%).

s a $94{ }^{\circ} \mathrm{C}, 40$ ciclos $\left(30 \mathrm{~s}\right.$ a $94^{\circ} \mathrm{C}, 30 \mathrm{~s}$ a $62{ }^{\circ} \mathrm{C}, 15 \mathrm{~min}$ a $72{ }^{\circ} \mathrm{C}$ ) y un ciclo de extensión final de $2.5 \mathrm{~min}$ a $72{ }^{\circ} \mathrm{C}$. Los productos de amplificación, que fueron de 750 pb aproximadamente, se visualizaron en gel de agarosa $1 \%$. Una vez obtenidas las secuencias, éstas se editaron y alinearon con los programas Finch TV 1.4.0.@ y Bio Edit Secuence Aligment Editor@. Para la identificación de especies, las secuencias se compararon con las reportadas en el banco de genes mediante el programa BLAST (GenBank, http:// www.ncbi.nlm.nih.gov). Posteriormente fueron depositadas en el Centro Nacional para la Información Biotecnológica (NCBI, por sus siglas en inglés).

\section{RESULTADOS Y DISCUSIÓN}

\section{Aislamientos}

Se obtuvieron 116 aislamientos, de los cuales 46 fueron de raíz (R), 52 de tallo (T) y 18 de espiga (E) (Cuadro 1). Los análisis moleculares permitieron eliminar algunas muestras que resultaron muy similares; por ejemplo, para RFLP fueron 101 aislados y para ISSR 103 aislados; finalmente se secuenciaron y subieron a NCBI 27 aislados. Las regio- nes geográficas de muestreo fueron de ambientes similares entre ellas y geográficamente cercanas (Figura 1); no obstante, el número de aislamientos varió tanto por región como por tipo de tejido en la planta. En las localidades de Las Jaras y La Estación fueron más frecuentes los aislamientos de los tallos, pero en la localidad Vista Hermosa los más frecuentes fueron los de raíz. Fue posible aislar hongos de la espiga en todas las localidades muestreadas con excepción de la localidad La Estrella.

Este hecho es importante, debido a que puede existir riesgo para la salud humana tanto por la destrucción del grano, como por la presencia de micotoxinas, ya que se ha reportado que el hongo sobrevive en residuos de cosecha y el cultivo es susceptible desde la emergencia, aunque la infección de la espiga es más frecuente durante la antesis (Burgess et al., 2001; Trail, 2009). El riesgo para la salud se encuentra latente si se toma en cuenta que en la región se practica la labranza mínima con rotaciones limitadas o de cereal-cereal, y podría esperarse encontrar residuos vegetales infectados en el suelo como fuente de inoculo desde la emergencia del cultivo (observaciones y experiencias directas de los autores). 
Cuadro 1. Número de aislamientos obtenidos por localidad y órgano de la planta.

\begin{tabular}{lccc}
\hline Lugar de muestreo & Raíz & Tallo & Espiga \\
\hline Las Jaras, Pénjamo, Gto. & 9 & 16 & 2 \\
La Estrella-1, Pénjamo, Gto. & 2 & 3 & 0 \\
La Estrella-2, Pénjamo, Gto. & 4 & 4 & 0 \\
Colorado de Herrera, Pénjamo, Gto. & 3 & 1 & 1 \\
La Estación, Pénjamo, Gto. & 7 & 10 & 7 \\
Vista hermosa, Pénjamo, Gto. & 13 & 12 & 1 \\
Maritas, Abasolo, Gto. & 3 & 3 & 2 \\
Los Prietos, Salamanca, Gto. & 5 & 3 & 5 \\
TOTAL & 46 & 52 & 18 \\
\hline
\end{tabular}

\section{Polimorfismos y agrupamientos moleculares}

\section{ITS-RFLP}

El fragmento ITS obtenido para todos los aislamientos fue de $1200 \mathrm{pb}$ aproximadamente, como se esperaba, y su longitud no diferenció a las cepas en estudio. Aún cuando se han diseñado iniciadores para los espaciadores internos transcritos que discriminan a Fusarium de otros géneros de hongos, existen reportes que indican que hay amplia variación dentro del género, por lo que no son del todo informativos por la amplia variabilidad encontrada (Arif et al., 2011; Abd-Elsalam et al., 2003). Por esta razón, en el presente estudio se optó por realizar un análisis RFLP para conocer la variabilidad en esta zona del genoma en los diferentes aislados y seleccionar sólo aquellas diferentes para los análisis de secuenciación.

Los perfiles de ADN obtenidos con los fragmentos de restricción fueron consistentes y reproducibles (Figura 3). Con las enzimas de restricción Hha I y Hae III se produjeron tres tipos de polimorfismo con cada una (Figuras $3 \mathrm{~A}$ y $B$, respectivamente), mientras que con la enzima Hinf I se identificaron solamente dos (Figura 3 C) lo que evidenció la diferencia entre los aislamientos obtenidos de las plantas de trigo. Aun cuando se encontraron múltiples similitudes en los perfiles de digestión del ADN, al integrar los datos de las tres enzimas en un dendrograma se originaron alrededor de 15 agrupamientos, no claramente definidos, pero que indicaron amplia variabilidad genética en esta zona (Figura 4).

Los agrupamientos RFLP no mostraron relación con las características morfológicas observadas; es decir, los grupos conformados no estuvieron relacionados con los grupos que presentaron alguna forma o color del micelio, o por la zona de aislamiento de la planta enferma; O'Donnell et al. (1998) denominaron crípticas a este tipo de especies.
No obstante, representantes de los agrupamientos resultantes se emplearon para la prueba de patogenicidad, seleccionando una cepa de cada uno.

\section{PCR-ISSR}

Los perfiles de ADN obtenidos con los dos iniciadores permitieron hacer una comparación genómica rápida entre los aislamientos. Para el análisis de los perfiles del iniciador (AC)8YG se consideraron las bandas de 400 a 2000 pb, mientras que para el iniciador $\mathrm{AC}(\mathrm{GACA})$, se tomaron en cuenta las ubicadas entre 400 y 1500 pb. Hubo diversidad de patrones o polimorfismos entre individuos de un mismo grupo (Figura 5). Con el iniciador AC(GACA), se visualizó un mayor número de bandas polimórficas (Figura 5 B), lo que evidenció diferencias entre las cepas. En el dendrograma que resultó con la información de los dos iniciadores se identificaron 14 agrupamientos definidos (Figura 6), lo que demostró la amplia variabilidad a nivel de ADN entre los aislados de Fusarium del presente estudio. Este resultado es similar a lo reportado por Consolo et al. (2015), quienes encontraron grupos genómicos relacionados de Fusarium graminearum. Cabe resaltar que cepas que conformaban un mismo grupo molecular ISSR fueron diferentes entre ellas en varias características como forma de micelio, coloración y velocidad de crecimiento y sin relación aparente con los grupos conformados con los marcadores RFLP. Lo anterior se debe a que los diferentes grupos conformados con los perfiles ISSR hacen referencia a similitudes a nivel de genoma y los grupos conformados con RFLPs sólo refieren una zona de $1200 \mathrm{pb}$.

\section{Secuenciación e identificación de especies}

Las secuencias obtenidas de los aislamientos seleccionados se compararon con las reportadas en el GenBank (http://www.ncbi.nlm.nih.gov) mediante el programa BLAST. La especie con mayor presencia fue Fusarium 

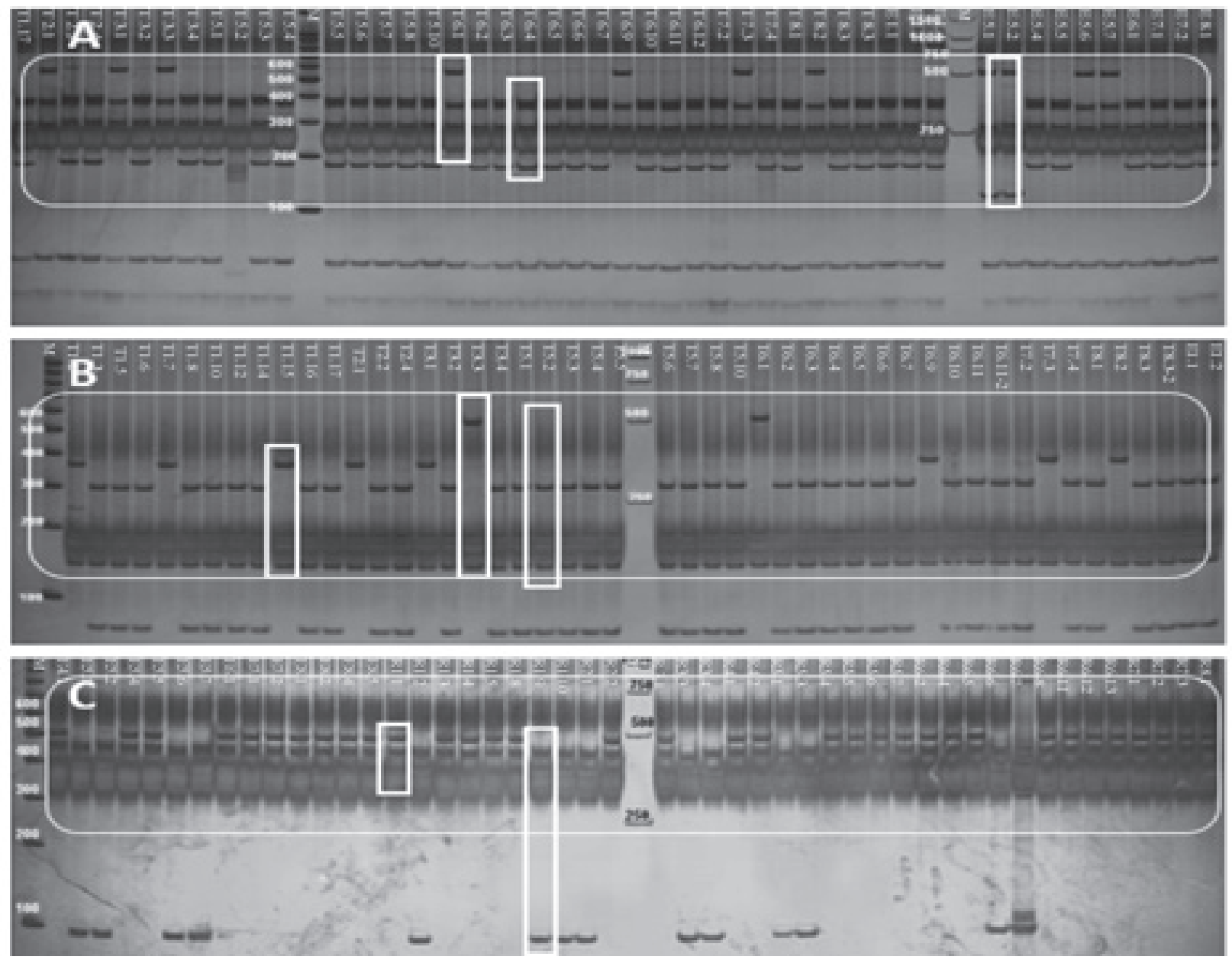

Figura 3. Perfiles de restricción del ADNr de la región ITS. Los rectángulos resaltan cada tipo de polimorfismo: A: tres tipos con la enzima Hha I; B: tres tipos con Hae III; C: dos tipos con Hinf I. Las muestras se identifican con el número de aislamiento asignado.

proliferatum, seguida de Fusarium subglutinans y Fusarium oxysporum (Cuadro 2), lo que coincide con lo reportado por Delgadillo (2008, Com. Pers.) ${ }^{\text {; }}$; pero además, se identificaron las especies Fusarium thapsinum y Fusarium andiyazi. Cabe hacer notar que, aun cuando las secuencias fueron comparadas a nivel de especie con información del banco de genes y actualmente disponibles con el número de accesión indicado, los aislamientos están referidos en NCBI como Fusarium spp.

Actualmente se están secuenciando otros genes para confirmar la especie reportada en el presente estudio, debido a que al analizar dos o más genes de los mismos aislamientos y comparar con las bases de datos la información, en algunos casos se refieren más nombres específicos; de ahí la importancia de que O'Donnell et al. (2000)

'Delgadillo S. F. (2008) Informe final de actividades del proyecto "Estudio para la identificación de los agentes causales de la pudrición de raíz y secado prematuro de cebada". Fundación Guanajuato Produce A. C. sugirieran el término de "Fusarium Species Complex" para definir grupos de especies emparentadas a nivel genómico, independientemente de la forma, color de micelio u hospedante.

Resultados similares han sido reportados en otros estudios en México; por ejemplo, Medina-Mendoza et al. (2014) reportaron una situación muy similar en aislamientos de Fusarium obtenidos de plantas de garbanzo (Cicer arietinum L.) con síntomas de fusariosis. Estos autores indicaron que no encontraron relación entre los rasgos morfológicos y los genómicos, pero al analizar el gen EF1-a fue posible agrupar a los aislamientos en complejos de especies. El árbol filogenético generado en el presente estudio con las secuencias del gen EF-1a de las cepas de Fusarium spp. seleccionadas y secuencias de referencia obtenidas del GenBank, indica que las especies encontradas, además de que fueron variadas, fueron las mismas causantes del daño, sin importar el tejido de las plantas de 


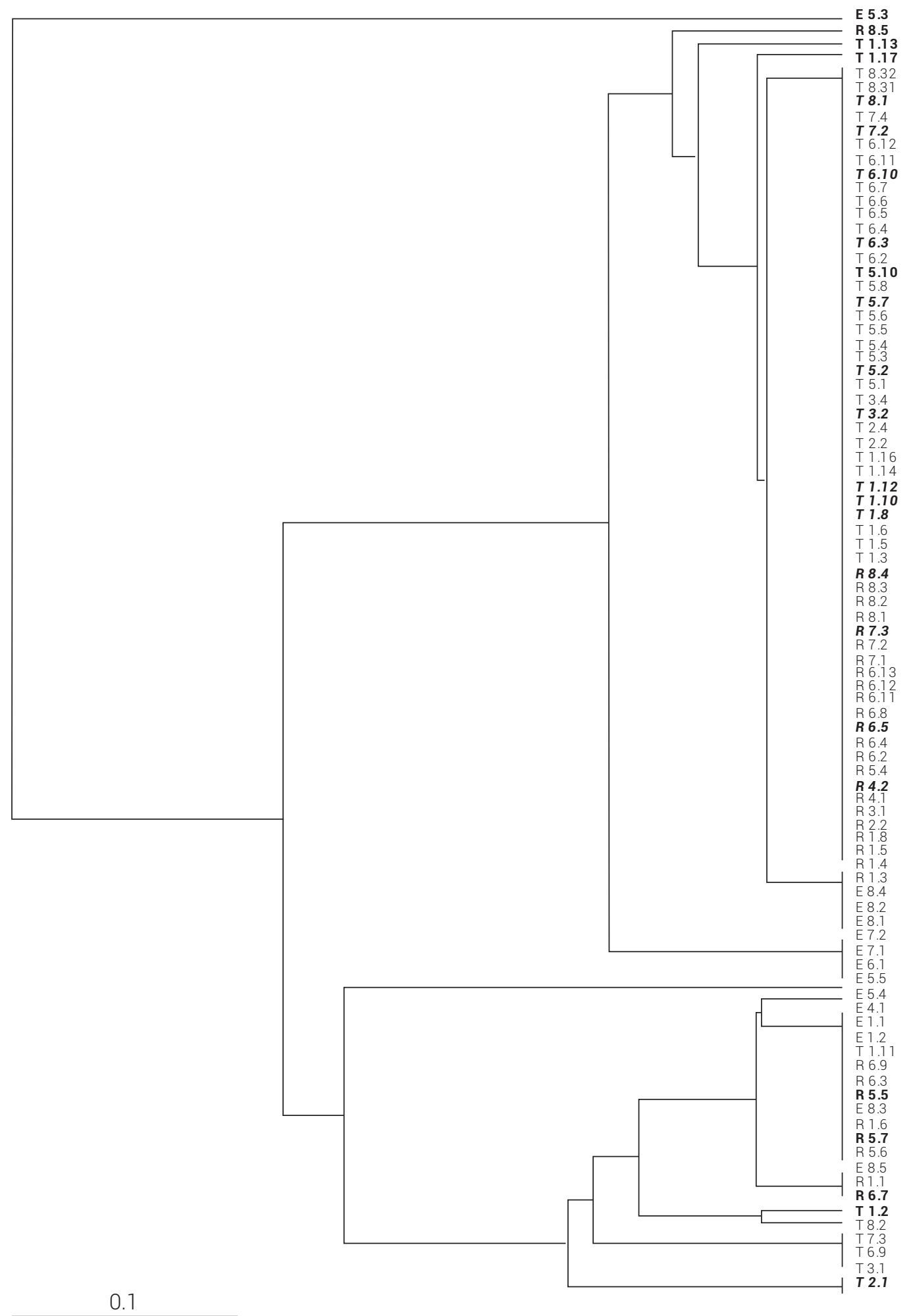

Figura 4. Dendrograma generado con base en los polimorfismos de longitud de fragmentos de restricción (RFLPs) de la región ITS con las enzimas Hha I, Hae III y Hinf I en diferentes aislados de Fusarium. Las cepas resaltadas con negritas fueron seleccionadas para las pruebas de patogenicidad y fueron secuenciadas. Las cepas resaltadas en italicas sólo se secuenciaron. 

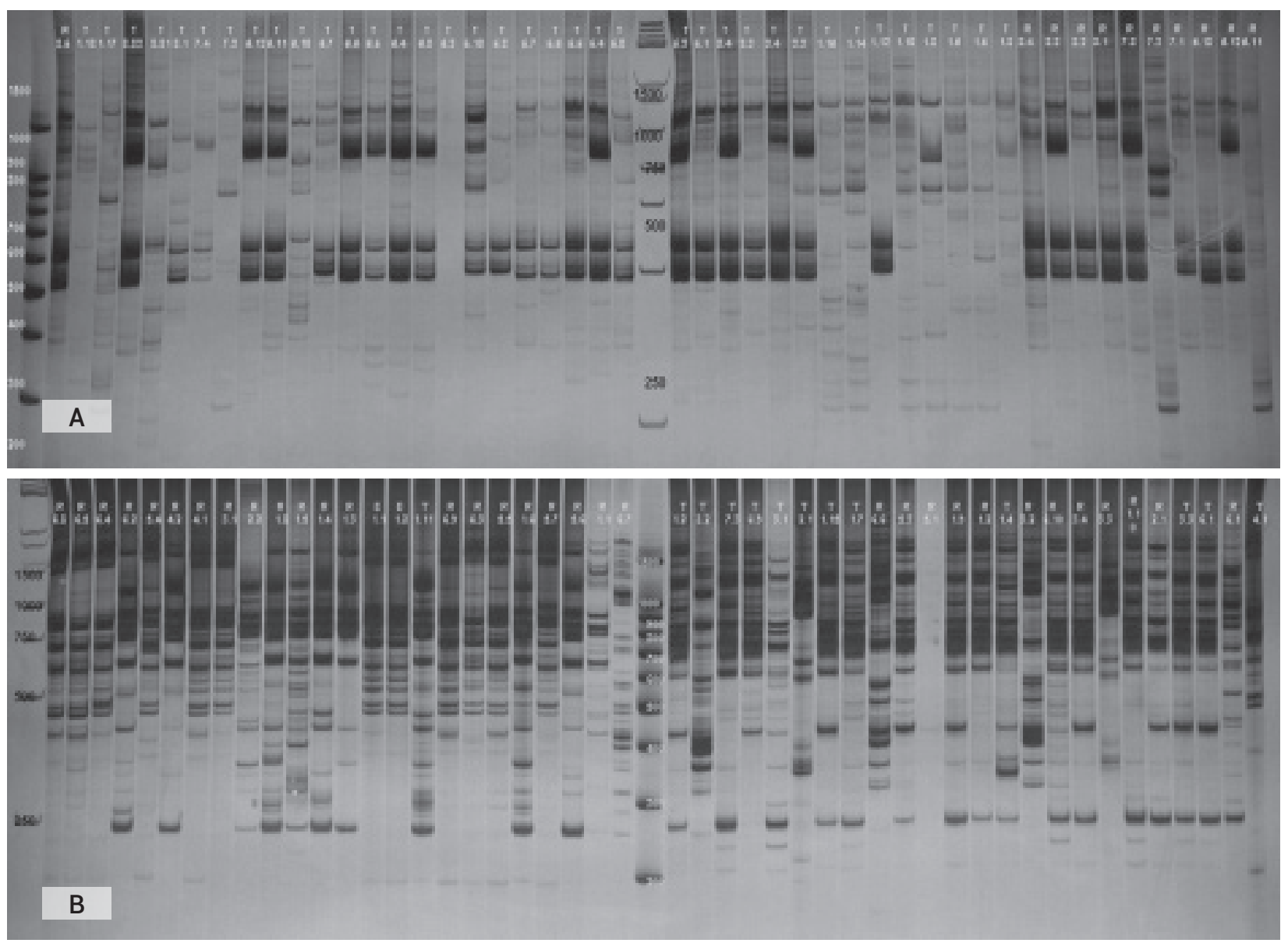

Figura 5. Perfiles de secuencia de repetición simple interna del ADN nuclear (ISSR) en diferentes aislados de Fusarium obtenidos de raíz y tallo de plantas de trigo con síntomas de amarillamiento: $\mathrm{A}$ : con el iniciador (AC) ${ }_{8} \mathrm{YG}$ y $\mathrm{B}$ : con el iniciador $\mathrm{AC}(\mathrm{GACA})_{4}$.

donde fueron asiladas. Es importante resaltar que aislamientos de la espiga continúan en estudio (Figura 7).

\section{Patogenicidad}

Se presentaron diferencias significativas entre tratamientos con respecto a la patogenicidad de las cepas (Tukey, 0.05; Cuadro 2). Fusarium afectó al sistema radical a diferentes niveles de severidad. Los tratamientos 5 (cepa T5.10, F. proliferatum) y 18 (combinación de las cepas E5.3, especie no identificada y R8.5, F. proliferatum) fueron los que produjeron mayor daño a las raíces; no así cuando se inocularon por separado las cepas de esta mezcla (tratamientos 1 y 2 , respectivamente). Por otro lado, el tratamiento 4 fue el menos patogénico (cepa T1.17, F. oxysporum). Los aislados más agresivos fueron tomados de cada una de esas estructuras (de tallo, T.510; de raíz, R8.5 y de la espiga, E5.3), lo que dañó considerablemente a las raíces en este ensayo. Lo anterior indica que no hubo especificidad por el origen del aislamiento (tipo de tejido) con respecto a la parte dañada de las plantas inoculadas (raíces), pero se demostró que algunos aislamientos fueron más agresivos que otros. En este sentido Fusarium puede afectar al sistema radical del trigo, independientemente de la parte de otras plantas de donde se haya obtenido el inóculo.

Con frecuencia se asocia a F. avenaceum, F. roseum, (o F. culmorum) y F. graminearum con pudriciones radicales (Cook, 1980), pero en este ensayo los tratamientos más agresivos se identificaron como F. proliferatum y ninguna de las especies mencionadas por Cook (1980) fue encontrada entre los aislamientos obtenidos en el Bajío (Cuadro 2, Figura 7). La presencia de F. proliferatum ya ha sido reportada con anterioridad en la zona por Delgadillo (2008, Com. Pers.) $)^{1}$ y Vega-Portillo et al. (2013).

\section{Consideraciones generales}

En el Bajío, entre las prácticas agronómicas usuales que predisponen al cultivo de trigo al ataque de hongos del suelo que causan pudriciones de raíz, espiga, tallo y muerte en preemergencia, se encuentran el monocultivo de cereales 


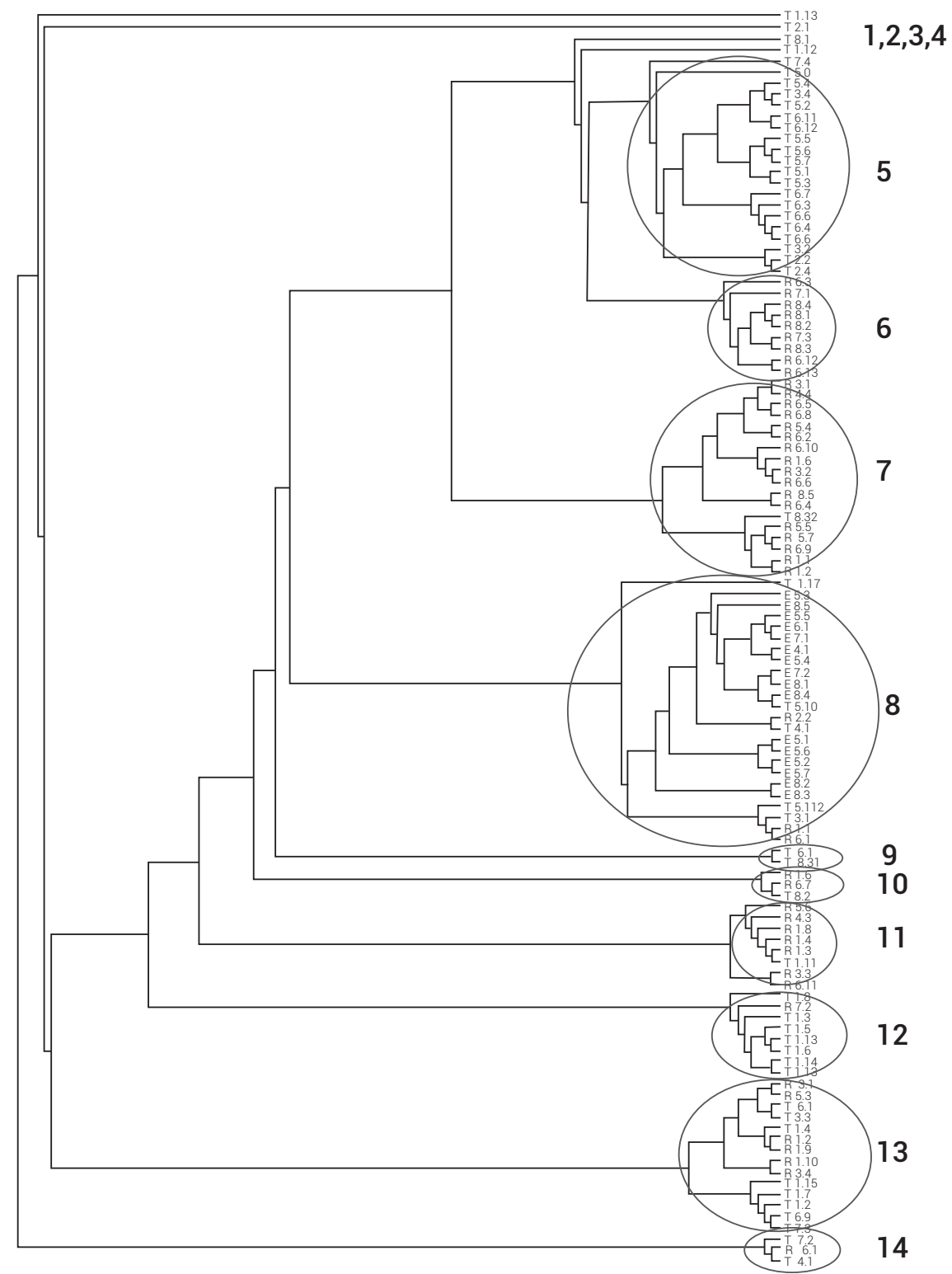

Figura 6. Agrupamiento genético de los aislamientos de Fusarium generado a partir de los perfiles de secuencia de repetición simple interna del ADN nuclear (PCR-ISSR) con los iniciadores (AC) 8YG y AC (GACA). Al realizar un corte transversal (línea resaltada vertical) se distinguen 14 grupos (en óvalos).

o la rotación de un cereal con otro cereal, la permanencia del rastrojo en el terreno (labranza de conservación), la aplicación de riegos de inundación, la mala nivelación del terreno y fertilizaciones con dosis mayores a $5 \mathrm{t} \mathrm{ha}^{-1}$. Otros factores que intervienen son el suelo tipo vertisol predominante en la región, rico en arcillas y el clima que va de templado a semi-seco (Delgadillo, 2008, Com. Pers'; Fernandez y Conner, 2011; Parsons, 2008, Com. Pers. ${ }^{2}$; SARH, 1992).

2Parsons M. W. (2008) Biotic and abiotic factors associated with Fusarium ear rot of maize caused by Fusarium verticillioides. PhD Dissertations. Iowa State University. Ames, lowa, USA. 161 p.
La distribución de las especies patogénicas está obviamente ligada a la distribución de sus hospedantes. Los factores como el tipo de suelo, el microambiente y el tipo de vegetación tendrán una gran influencia. Muchas especies de Fusarium tienen distribuciones controladas por el medio ambiente (Backhouse et al., 2001; Booth, 1971; Slafer et al., 2001). En el presente estudio, los sitios de muestreo estuvieron geográficamente cercanos y con microclimas similares (1700 msnm, semicálido seco) (Delgadillo, 2008, Com. Pers.'; Figura 1), diferente a los de otras zonas trigueras (Cook, 1980), por lo que no se esperaba encontrar las mismas especies de Fusarium reportadas para el mismo hospedante en ambientes distintos. 
Cuadro 2. Severidad de la enfermedad como porcentaje de infección e identificación de las especies con base en la secuenciación del gen EF-1a.

\begin{tabular}{|c|c|c|c|c|c|}
\hline Tratamiento & $\%$ sev. & Agrup. $^{+}$ & & Cepas $^{+\dagger}$ & Especie \\
\hline 5 & 39.75 & a & & T5.10 & F. proliferatum \\
\hline 18 & 27 & a & & E5.3, R8.5 & Mezcla \\
\hline 22 & 22.5 & $b$ & & R8.5, T1.13, T1.17, T5.10, R5.5, R5.7, R6.7 & Mezcla \\
\hline 9 & 18 & b & & $\mathrm{T} 1.2$ & F. proliferatum \\
\hline 7 & 16.5 & b & & R5.7 & F. proliferatum \\
\hline 6 & 16.25 & $b$ & & R5.5 & F. proliferatum \\
\hline 24 & 15.75 & $b$ & & R8.5, T1.15, R6.10, E5.1, E5.2, R1.10, T6.1 & Mezcla \\
\hline 27 & 15.25 & $b$ & & T1.2, T1.15, R6.10, E5.1, E5.2, R1.10, T6.1 & Mezcla \\
\hline 23 & 14.75 & $b$ & & $\mathrm{R} 8.5, \mathrm{~T} 1.2$ & F. proliferatum \\
\hline 8 & 13.5 & $b$ & & $\mathrm{R} 6.7$ & F. oxysporum \\
\hline 13 & 12 & $b$ & & E5.2 & No identificado \\
\hline 15 & 11.25 & & c & T6.1 & F. subglutinans \\
\hline 12 & 11 & & c & E5.1 & No identificado \\
\hline 25 & 9.5 & & c & T1.2, T1.13, T1.17, T5.10, R5.5, R5.7, R6.7 & Mezcla \\
\hline 2 & 9.5 & & c & R8.5 & F. proliferatum \\
\hline 16 & 9 & & c & T1.13, T1.17, T5.10, R5.5, R5.7, R6.7 & Mezcla \\
\hline 19 & 8.75 & & c & E5.3, T1.13, T1.17, T5.10, R5.5, R5.7, R6.7 & Mezcla \\
\hline 26 & 8 & & c & $\begin{array}{l}\text { T1.13, T1.17, T5.10, R5.5, R5.7, R6.7, T1.15, } \\
\text { R6.10, E5.1, E5.2, R1.10, T6.1 }\end{array}$ & Mezcla \\
\hline 14 & 7.75 & & c & $\mathrm{R} 1.10$ & No identificado \\
\hline 21 & 7.5 & & c & E5.3, T1.15, R6.10, E5.1, E5.2, R1.10, T6.1 & Mezcla \\
\hline 3 & 7.5 & & c & $\mathrm{T} 1.13$ & F. thapsinum \\
\hline 11 & 6.5 & & c & R6.10 & F. proliferatum \\
\hline 1 & 5.75 & & c & E5.3 & No identificado \\
\hline 10 & 5.5 & & c & $\mathrm{T} 1.15$ & F. subglutinans \\
\hline 17 & 5.25 & & c & T1.15, R6.10, E5.1, E5.2, R1.10, T6.1 & Mezcla \\
\hline 20 & 4 & & c & E5.3, T1.2 & Mezcla \\
\hline 4 & 2.25 & & c & $\mathrm{T} 1.17$ & F. oxysporum \\
\hline 28 & 0 & & c & AGUA & -------------- \\
\hline
\end{tabular}

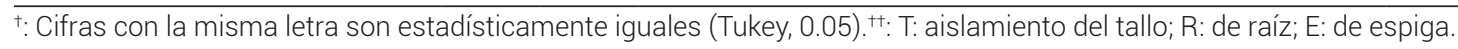

Cabe destacar que aunque F. proliferatum es una especie cosmopolita, no siempre es patogénica, y que ataca a una amplia diversidad de especies vegetales incluyendo gramíneas, piña (Ananas comosus L.), espárrago (Asparagus officinalis L.), liliáceas, etc. (Stepień et al., 2011). En el presente estudio resultó la más común y la más agresiva, que además fue aislada de raíz, tallo y espiga. También se ha reportado en cebada (Delgadillo, 2008, Com. Pers."; Vega-Portillo et al., 2013), entre otras especies como F. verticillioides y F. graminearum (40 y 60 \% de la población, respectivamente).
La caracterización molecular permitió diferenciar y relacionar la identidad de los aislamientos con base en la comparación de las secuencias de ADN resultantes. Así, los ITS-RFLP mostraron las diferencias en las regiones del ADN ribosomal, que en nuestro estudio diferenciaron claramente a los aislamientos, pero los polimorfismos no se asociaron con alguna especie en particular. Por otro lado, los ISSR utilizados, aun cuando fueron sólo dos iniciadores, éstos lograron separar los aislamientos en 14 grupos definidos, que evidenciaron la variabilidad genética de los aislados del complejo Fusarium. 


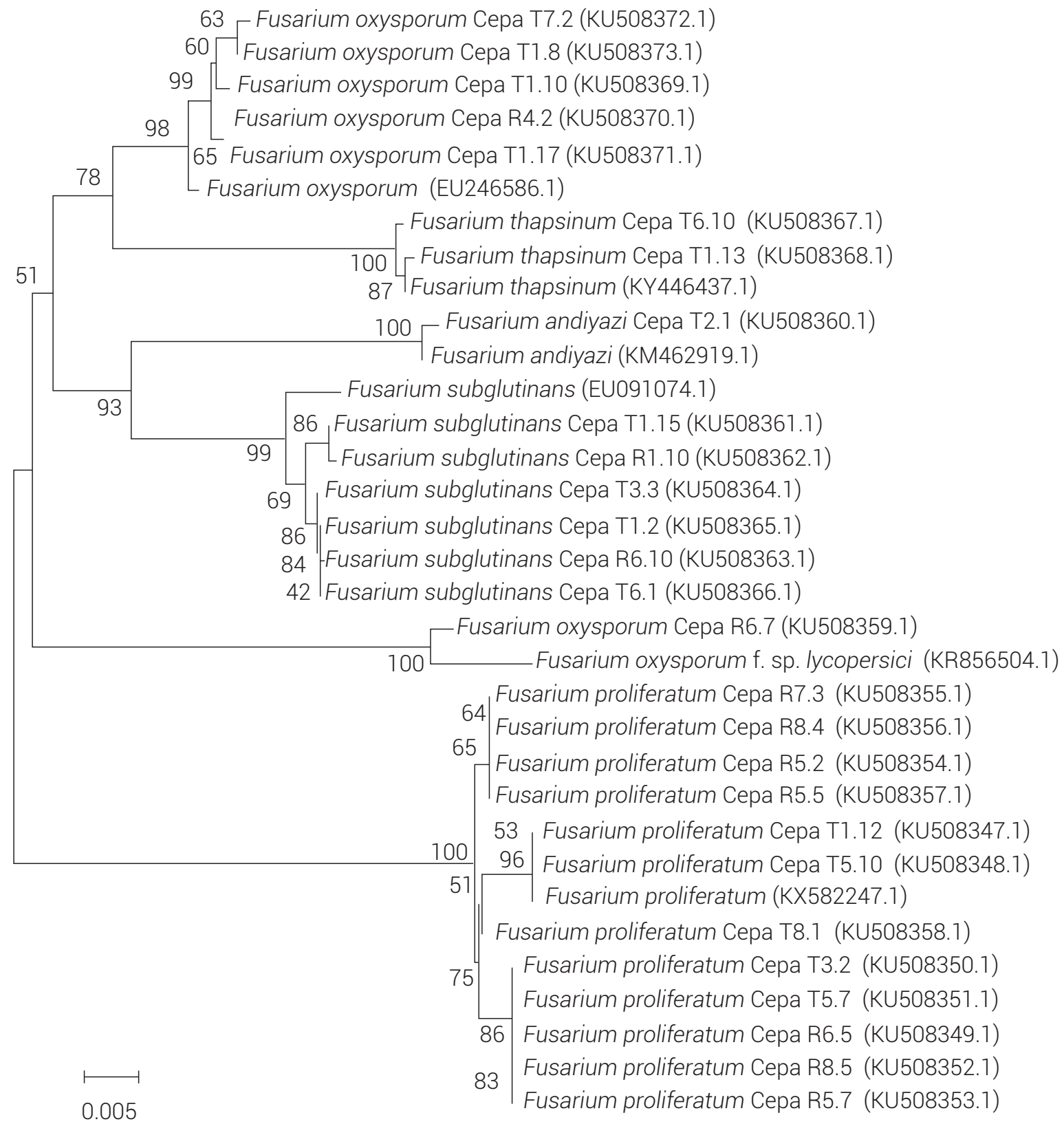

Figura 7. Árbol filogenético generado a partir de la secuenciación del gen EF-1a de las cepas de Fusarium spp. aisladas de trigo con los síntomas de amarillamiento. La reconstrucción filogenética se obtuvo mediante el método de Neighbor Joining con 10000 remuestreos. El número entre paréntesis adelante de cada cepa corresponde al número de accesión asignado por el Genbank. Los números de accesiones cuya inicial es "KU" corresponden a las secuencias obtenidas en el presente estudio, las otras accesiones fueron utilizadas como puntos de comparación y obtenidas del GenBank.

\section{CONCLUSIONES}

Se caracterizó e identificó molecularmente y se evaluó la patogenicidad de las especies de Fusarium asociadas al amarillamiento o madurez prematura en el cultivo de trigo en el sur del Bajío guanajuatense. Con esta información se identificaron las especies F. proliferatum, F. subgluti- nans, F. oxysporum, F. thapsinum y F. andiyazi asociadas a la enfermedad. Las cepas tuvieron efectos diferentes de patogenicidad al inocularse individualmente o en mezcla, aun entre cepas de la misma especie. La mayor patogenicidad se identificó en la cepa T5.10 (F. proliferatum) y en efecto conjunto de las cepas R 8.5 (F. proliferatum) y E5.3 (no identificado). 


\section{BIBLIOGRAFÍA}

Abd-Elsalam K. A., I. N. Aly, M. A. Abdel-Satar, M. S. Khalil and J. A. Verreet (2003) PCR identification of Fusarium genus based on nuclear ribosomal-DNA sequence data. African Journal of Biotechnology 2:82-85.

Albayrak G., E. Yörük, A. Gazdağli and B. Sharifnabi (2016) Genetic diversity among Fusarium graminearum and $F$. culmorum isolates based on ISSR markers. Archives of Biogical Sciences 68:333343.

Arif M., D. R. Pani, N. W. Zaidi and U. S. Singh (2011) PCR-based identification and characterization of Fusarium sp. associated with mango malformation. Biotechnology Research International. DOl.org/10.4061/2011/141649.

Azofeifa-Delgado A. (2006) Uso de marcadores moleculares en plantas; aplicaciones en frutales del trópico. Agronomía Mesoamericana 17:221-242.

Backhouse D., L. W. Burgess and B. A. Summerell (2001) Biogeography of Fusarium. In: Fusarium. B. A. Summerell, J. F. Leslie, D. Backhouse, W. L. Bryden and L. W. Burgess (eds.). APS Press. St Paul, Minnesota, USA. pp:122-137.

Barnett H. L. and B. B. Hunter (1972) Illustrated Genera of Imperfect Fungi. 3er ed. Burgess Publishing Company. Minneapolis, Minnesota, USA. 241 p.

Booth C. (1971) The Genus Fusarium. Commonwealth Agricultural Bureaux. Commonwealth Mycological Institute. Kew, Surrey, England. $237 p$

Burgess L. W., D. Backhouse, B. A. Summerell and L. J. Swan (2001) Crown rot of wheat. In: Fusarium. B. A. Summerell, J. F. Leslie, D. Backhouse, W. L. Bryden and L. W. Burgess (eds.). APS Press. St. Paul, Minnesota, USA. pp:271-294.

Consolo V. F., L. M. Ortega, G. Salerno, A. L. Astoreca and T. M. Alconada (2015) Genetic diversity of Fusarium graminearum sensu lato isolates from wheat associated with Fusarium Head Blight in diverse geographic locations of Argentina. Revista Argentina de Microbiología 47:245-250.

Cook R. J. (1980) Fusarium foot rot of wheat and its control in the Pacific Northwest. Plant Disease 64:1061-1066.

Doyle J. J. and J. L. Doyle (1987) A rapid DNA isolation procedure for small quantities of fresh leaf tissue. Phytochemical Bulletin 19:11-15.

FAOSTAT, Food and Agriculture Organization of the United Nations (2015) Food and agriculture data. Food and Agriculture Organization of the United Nations. Rome, Italy. http://faostat.fao.org (Marzo, 2015).

Fernandez M. R. and R. L. Conner (2011) Root and crown rot of wheat. Prairie Soils and Crops Journal 4:151-157.

French E. R. y T. T. Hebert (1982) Métodos de Investigación Fitopatológica. Instituto Interamericano de Cooperación para la Agricultura (IICA). San José, Costa Rica. 289 p.

Gilchrist-Saavedra L., G. Fuentes-Dávila, C. Martínez-Cano, R. M. LópezAtilano, E. Duveiller, R. P. Singh, M. Henry e I. García A. (2005) Guía Práctica para la Identificación de Algunas Enfermedades de Trigo y Cebada. 2a edición. CIMMYT. México, D. F. 68 p.

González C. M. M. y J. Simpson (1997) Diversidad genética en hongos. In: Tópicos Selectos de Fitopatología: Genética Molecular. J. P. Martínez S. y A. D. Martínez-Espinoza (eds.). Sociedad Mexicana de Fitopatología. Centro de Investigación y de Estudios Avanzados. México. pp:4-23.

Medina-Mendoza C., G. M. Beltrán-Ríos, A. López-López, L. X. Zelaya-Molina and E. Valadez-Moctezuma (2014) Characterization and identification of Fusarium species complexes affecting chickpea with total protein profiles, EF-1a gen. Annual Research \& Review in Biology 4:3513-3523

Nelson P. E., T. A. Toussoun and W. F. O. Marasas (1983) Fusarium Species: an Illustrated Manual for Identification. The Pennsylvania State University Press. University Park, PA. $193 p$

O'Donnell K., H. I. Nirenberg, T. Aoki and E. Cigelnik (2000) A multigene phylogeny of the Gibberella fujikuroi species complex: detection of additional phylogenetically distinct species. Mycoscience 41:61-78.

O'Donnell K., H. C. Kistler, E. Cigelnik and R. C. Ploetz (1998) Multiple evolutionary origins of the fungus causing Panama disease of banana: concordant evidence from nuclear and mitochondrial gene genealogies. Proceedings of the National Academy of Sciences of the United States of America 95:2044-2049.

O'Donnell K. (1992) Ribosomal DNA internal transcribed spacers are highly divergent in the phytopathogenic ascomycete Fusarium sambucinum (Gibberella pulicaris). Current Genetics 22:213-220

Sambrook J., E. F. Fritsch and T. Maniatis (1989) Molecular Cloning: A Laboratory Manual. 2nd ed. Cold Spring Harbor Laboratory Press. New York. 585 p.

Sánchez-Coello N. G., M. Luna-Rodríguez, M. Vázquez-Torres, L. R. SánchezVelásquez, N. Santana-Buzzy, P. Octavio-Aguilar y L. G. Iglesias-Andreu (2012) Optimización de un protocolo de aislamiento del ADN y de un sistema de amplificación ISSR-PCR para Ceratozamia mexicana Brongn. (Zimiaceae). Revista Chapingo Serie Ciencias Forestales y del Ambiente 18:123-133.

SARH, Secretaria de Agricultura y Recursos Hidráulicos. Dirección General de Sanidad Vegetal (1992) Guía fitosanitaria para el cultivo de trigo. Serie Sanidad Vegetal. Sistema Producto Trigo. Secretaria de Agricultura y Recursos Hidráulicos. México, D. F. 279 p.

SIAP, Servicio de Información Agroalimentaria y Pesquera (2015) Avance de siembras y cosechas. Resumen nacional por estado. Servicio de Información Agroalimentaria y Pesquera, SAGARPA. México, D.F. http://infosiap.siap.gob.mx:8080/agricola_siap_gobmx/ AvanceNacionalCultivo.do;jsessionid=F174E216F48078A9AAF 50A11D3104D90. http://www.siap.gob.mx (Marzo 2015).

Slafer G. A., L. G. Abeledo, D. J. Miralles, F. G. González and E. M. Whitechurch (2001) Photoperiod sensitivity during stem elongation as an avenue to raise potential yield in wheat. Euphytica 119:191-197.

Stepień L., G. Koczyk and A. Waśkiewicz (2011) Genetic and phenotypic variation of Fusarium proliferatum isolates from different host species. Journal of Applied Genetics 52:487-496.

Trail F. (2009) For blighted waves of grain: Fusarium graminearum in the postgenomics era. Plant Physiology 149:103-110.

Valadez M. E. y G. Kahl (2005) Huellas de DNA en Genomas de Plantas. Teoría y Protocolos de Laboratorio. Universidad Autónoma de Chapingo. Mundi-Prensa. México, D.F. 147 p.

Vega-Portillo H. E., S. G. Leyva-Mir, H. E. Villaseñor-Mir y O. G. Alvarado-Gómez (2013) Identificación de Fusarium spp. asociadas a espigas blancas y pudrición de raíz de trigo en los valles altos y Bajío de México. Revista Mexicana de Fitopatología 31:S90.

Vega-Ramos K. L., J. X. Uvalle-Bueno and J. F. Gómez-Leyva (2013) Molecular variability among isolates of Fusarium oxysporum associated with root rot disease of Agave tequilana. Biochemical Genetics 51:243-255.

Wall P. (1988) Central and South America. In: Wheat Production Constraints in Tropical Environments. A Proceedings of the International Conference. A. R. Klatt (ed.). January 19-23 1987, Chiang Mai, Thailand. CIMMYT. Mexico, D. F. pp:27-34.

Weising K., H. Nybom, K. Wolff and G. Kahl (2005) DNA Fingerprinting in Plants, Principles, Methods and Applications. 2nd edition. CRC Press, Taylor \& Francis Group. Boca Raton, Florida, USA. 444 p.

White T. J., T. Bruns, S. Lee and J. Taylor (1990) Amplification and direct sequencing of fungal ribosomal RNA genes for phylogenetics. In: PCR Protocols: A Guide to Methods and Applications. M. A Innis, D. H. Gelfand, J. J. Sninsky and T. J. White (eds.). Academic Press. New York, USA. pp:315-322. 